K

линическое значение генетической вариабельности генитальных микоплазм

\author{
К.И. Плахова
}

ФГБУ «Государственный научный центр дерматовенерологии и косметологии» Минздрава России 107076, Москва, ул. Короленко, дом 3, стр. 6

\footnotetext{
Приведены данные о генетической вариабельности генитальных микоплазм. Показаны результаты изучения генетической вариабельности M. hominis по гену vaa, U. parvum по гену mba и M. genitalium по гену mg192, полученных от женщин с различными клиническими проявлениями воспалительных заболеваний мочеполовой системы. По результатам молекулярного типирования 138 образцов генитальных микоплазм показано наличие ассоциации между клиническими проявлениями воспалительных заболеваний мочеполовой системы, вызванных U. parvum и различными сероварами U. parvum, а также различными генетическими вариантами M. hominis. Инсрицирование сероваром 6 U. parvum приводит к развитию воспалительных заболеваний мочеполового тракта, сопровождающихся субъективными проявлениями $(p<0,05)$. Генетический вариант II M. hominis чаще идентифицировали у пациенток с наличием клинических проявлений воспалительных заболеваний; вариант I — у пациенток, инфицированных M. hominis, без признаков воспаления $(p<0,05)$. Определены генетические варианты M. genitalium, значимых различий распределения которых у обследованных пациенток не установлено.
}

Ключевые слова: ген mba U. parvum, серовары U. parvum, ген vaа M. hominis, ген mg 192 M. genitalium, молекулярное типирование.

Контактная информация: plahova_xenia@mail.ru. Вестник дерматологии и венерологии 2015; (2): 76—83.

\title{
Genetic variability of genital mycoplasmas and its clinical value
}

\section{K.I. Plakhova}

State Research Center of Dermatovenereology and Cosmetology, Ministry of Healthcare of the Russian Federation Korolenko str., 3, bldg 6, Moscow, 107076, Russia

The article presents data on genetic variability of genital mycoplasmas. The author presents the results of genetic variability studies for M. hominis, gene vaa, U. parvum, gene mba, and M. genitalium, gene mg192, sampled from women with different clinical manifestations of inflammatory diseases of the urogenital system. Based on the molecular typing results for 138 samples of genital mycoplasmas, the author revealed a relationship between clinical manifestations of inflammatory diseases of the urogenital system caused by U. parvum and different $U$. parvum serovars as well as different genetic variations of M. hominis.Infection with $6 \mathrm{U}$. parvum serovar results in the development of inflammatory diseases of the urogenital tract accompanied by subjective manifestations $(p<0.05)$. Genetic variant II of $M$. hominis was revealed more often in patients with clinical manifestations of inflammatory diseases while variant I was revealed more often in patients infected with $M$. hominis without any signs of inflammation $(p<0.05)$. Genetic variants of $M$. genitalium were determined; no significant differences in terms of their prevalence in the examined patients were revealed.

Key words: mba U. parvum gene, U. parvum serovars, vaa M. hominis gene, mg 192 M. genitalium gene, molecular typing.

Corresponding author: plahova_xenia@mail.ru. Vestnik Dermatologii i Venerologii 2015; 2: 76—83. 
Mycoplasma hominis, M. genitalium, Ureaplasma spp. - представители класcа Molicutes, относятся к различным фрилогенетическим группам внутри класca: M. genitalium и Ureplasma spp. к группе Pneumoniae; M. hominis к группе Hominis. Генитальные микоплазмы обладают тропностью к слизистой оболочке мочеполовой системы человека и колонизируют в основном нижние ее отделы. Отличительными особенностями этой группы микроорганизмов являются минимальных размеров геном и низкая метаболическая активность [1].

Клиническая роль M. hominis, M. genitalium, Ureaplasma spp. различна, при этом клинические проявления характеризуются воспалительными процессами мочеполовой системы человека. Результаты некоторых исследований позволяют связывать особенности развития воспалительных заболеваний, вызванных генитальными микоплазмами, с их метоболической активностью. Установлено, что M. hominis и Ureaplasma spp., метаболизм которых осуществляется по гликолитическому пути, являются условно-патогенными микроорганизмами. По результатам исследований последних лет U. urealyticum и M. hominis могут выявляться при бактериальном вагинозе, инфицирование ими связывают с развитием воспалительных заболеваний нижних отделов мочеполового тракта, воспалительных заболеваний органов малого таза (сальпингитах, эндометритах), а также при патологии беременности (преждевременных родах) и неонатальных инфекциях. В то же время известно, что M. hominis и Ureaplasma spp. часто идентифрицируются у здоровых лиц, что подтверждается клиническими и лабораторными исследованиями [1-3].

M. genitalium, метаболизм которого осуществляется по негликолитическому пути, является абсолютным патогеном. Инфицирование M. genitalium приводит к развитию негонококкового уретрита у мужчин и цервицита, воспалительных заболеваний органов малого таза у женщин.

Классические микробиологические исследования генитальных микоплазм не привели к пониманию механизмов, влияющих на их вирулентность. Патогенетический потенциал условно-патогенных M. hominis, Ureaplasma spp. и механизмы развития различных воспалительных заболеваний мочеполовой системы, вызванных M. genitalium, не определены. Метаболические свойства этих микроорганизмов и маленький размер осложняют их изучение, в связи с этим наибольший интерес представляют молекулярно-генетические исследования, а именно: поиск и изучение генов, кодирующих ключевые белки, которые осуществляют адгезивную и антигенную функции, определяя вирулентные свойства микроорганизма.

Известно, что генитальные микоплазмы обладают геномом, который характеризуется выраженной вариабельностью, в том числе внутри штамма. Кроме того, размер генома может меняться не только вну- три одного рода, вида, но и в пределах штамма. Эта особенность обусловливает высокую изменчивость генетических и фенотипических свойств микоплазм. Антигенные свойства этих микроорганизмов в значительной степени различаются в зависимости от штамма. Именно с этими свойствами микоплазм связывают широкий спектр возможных клинических проявлений - от воспалительных заболеваний мочеполовой системы до полного их отсутствия.

В 2000 г. геном Ureaplasma spp. был полностью секвенирован, при этом установлено, что его размер составляет 751 bp [4-6], позже были определены размеры генома M. genitalium и M. hominis: 665 и 580 bр соответственно. Установлено, что между U. parvum и M. hominis 46 перекрестных генов, между U. parvum и M. genitalium 40 генов, между M. hominis и M. genitalium лишь 24. Перекрестные гены регулируют метаболизм микроорганизмов и определяют близкие клинические проявления у инфрицированных U. parvum и M. hominis пациентов $[1,7,8]$.

Современная классификация ряда микроорганизмов основывается на вариабельности поверхностных белков и генов, их кодирующих. Исследования, направленные на изучение генетической вариабельности Ureaplasma spp., дали возможность классифицировать эти микроорганизмы на основании генетических различий. В 2000 г. было определено два биовара [9] (рисунок), при этом Ureaplasma parvum включает 4 серовара: 1, 3, 6 и 14. Авторы исследования показали, что наиболее близкими по генетической структуре являются серовары 3 и 14, наиболее отличающимся от остальных сероваров - серовар 6, который выделен в отдельную филогенетическую ветвь. Разделение на серовары основано на вариабельности гена mba. Мембранный поверхностный белок MBA (multiple-banded antigen) $U$. parvum обладает выраженными антигенными свойствами. Ген mba имеет нестабильную и вариабельную структуру, состоит из относительно консервативного 5'-отрезка и переменной 3'-области, содержащей однородные повторяющиеся элементы, что определяет патогенный потенциал и обусловливает высокую изменчивость генетических и фенотипических свойств Ureaplasma spp. Уклонению от иммунного ответа и длительному латентному существованию микроорганизма способствует антигенное разнообразие белка MBA, которое обеспечивается изменением числа повторяющихся звеньев в структуре переменной области. Известно, что именно 3'-область гена mba может быть различной в пределах одного штамма $[9,10]$. Результаты этого исследования авторы обозначили как перспективу определения механизмов и степени вирулентности условно-патогенного микроорганизма U. parvum. Однако дальнейшие исследования в основном носили описательный характер, анализ клинических проявлений у инфицированных пациентов и их взаимосвязи с генетическими вариантами U. parvum не проводился. 


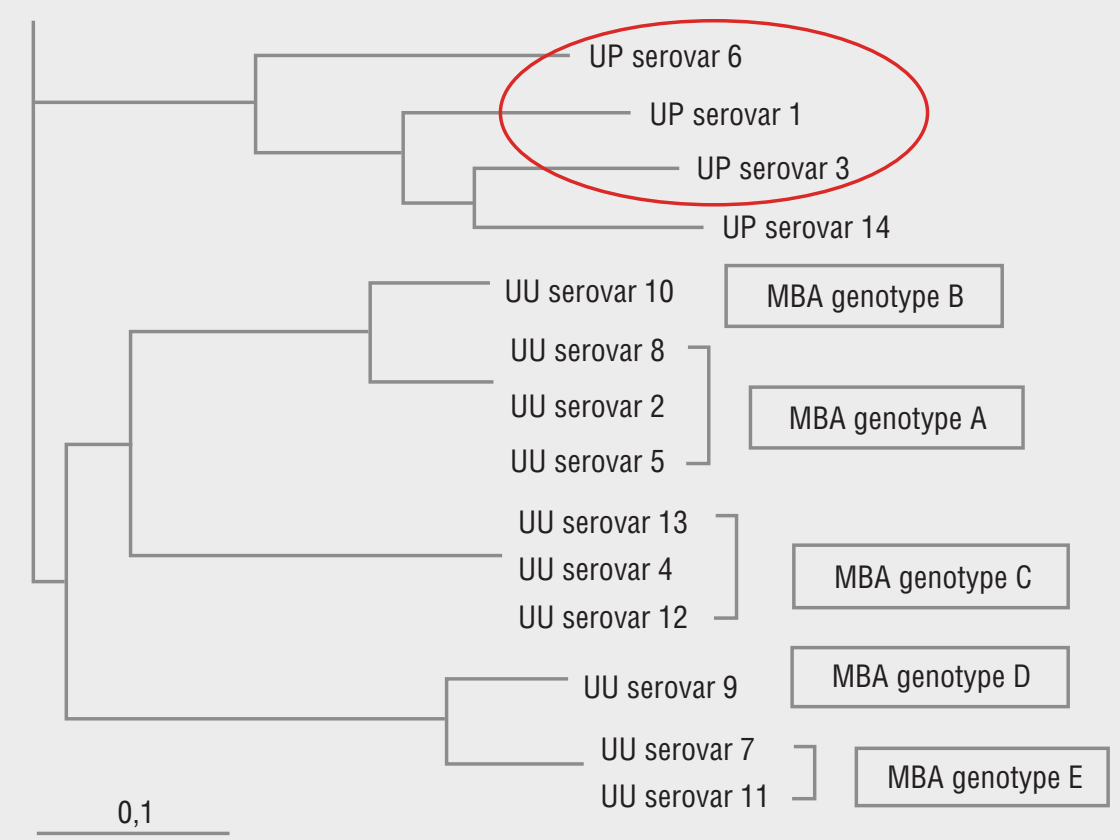

Рисунок Филогенетическое дерево по результатам секвенирования по гену mba, включающее 14 сероваров Ureaplasma parvum (UP) и U. urealyticum (UU) [Kong F. et al, 2000]

Генетическая классификация M. hominis основана на вариабельности гена vaа, кодирующего белок VAA (variable adherence-associated antigen), который обладает антигенными свойствами и является ключевым белком, участвующим в процессе адгезии микроорганизма. В 2001 г. датский ученый Т. Boesen и соавт. выделили 6 типов (категорий, вариантов) гена vaa. Вариабельность гена vаa достигается специфическим набором генных кассет (или модулей), определяющим уникальную первичную структуру. Всего выделено 8 вариантов модулей, два из которых постоянные, остальные в различной последовательности составляют структуру гена, при этом не все модули входят в состав структуры каждого варианта гена [11, 12].

Показано, что именно изменчивость поверхностного белка VAA и вариабельность гена, его кодирующего, влияют на адгезивные свойства M. hominis. Исследователи предполагают, что эта генетическая вариабельность M. hominis может определять различные клинические проявления у инфицированных пациентов, но изучение взаимосвязи генетических вариантов и клинических проявлений не проводилось [11-13].

В основе изучения генетической вариабельности M. genitalium лежат исследования структуры и функционирования оперона $\mathrm{MgPa}$, который кодирует три белка: MG190 (mgpA), MG191 (mgpВ или P140) и MG192 (mgpC или Р110). Два последних белка являются поверхностными и ключевыми в процессе адгезии M. genitalium, гены, их кодирующие, вариабельны и, как предполагается, определяют антигенную изменчивость [14].

Определение генетических вариантов микроорганизмов и вариабельности ключевых, поверхностных антигенных белков является перспективным направлением изучения вирулентности микроорганизмов. Выяснение клинической значимости генетических вариантов микроорганизмов требует проведения исследований, одновременно включающих определение генетических вариантов микроорганизмов, полученных от пациентов, и тщательного клинического и лабораторного обследований.

В период с 2012 по 2014 г. в ФГБУ «ГНЦДК» Минздрава России проведено изучение генетических вариантов генитальных микоплазм и их взаимосвязи с клиническими проявлениями воспалительных заболеваний мочеполовой системы.

Цель исследования: изучить генетическую вариабельность $M$. hominis по гену vaa, U. parvum по гену mba и M. genitalium по гену mg192, выделенных из образцов биологического материала, полученного от женщин с различными клиническими проявлениями воспалительных заболеваний мочеполовой системы и клинически здоровых женщин (для M. hominis, U. parvum ). 


\section{Материал и методы}

В ходе выполнения исследования использовались клинические, лабораторные методы, а также методы статистической обработки.

В исследование включены пациентки, обратившиеся в КДЦ ФГБУ «ГНЦДК» Минздрава России с жалобами со стороны мочеполовой системы, а также для профилактического обследования.

Для изучения генетической вариабельности U. parvum, M. hominis и M. genitalium отобраны вариабельные гены, кодирующие поверхностные белки, которые определяют антигенные и адгезивные свойства генитальных микоплазм.

Изучение генетической вариабельности Ureaplasma parvum (по гену mba), vaа Mycoplasma hominis (по гену vaа) и mg192 Mycoplasma genitalium (по гену mg192) осуществлялось методом секвенирования с использованием генетического анализатора 3130 Genetic Analyzer, с последующим анализом нуклеотидных последовательностей гена с помощью компьютерной программы MEGA5. Амплифрикация вариабельно- го участка генов осуществлялась с использованием праймеров, представленных в табл. 1.

В исследование включено 138 полученных от пациенток образцов, содержащих генитальные микоплазмы.

Основные критерии включения в исследование:

возраст женщины 20-40 лет;

идентификация одного из трех микроорганизмов (U. parvum, M. hominis или M. genitalium) в биологическом материале (соскоб уретры, цервикального канала и материал заднего свода влагалища) методом полимеразной цепной реакции (ПЦР) и/или культуральным методом (DUO, Biorad; для идентифрикации М. hominis).

Из исследования исключались пациентки, у которых по результатам лабораторного обследования методом ПЦР и/или культуральным методом выявлены C. trachomatis, N. gnorrhoeae, T. vagonalis, вирус простого герпеса, условно-патогенные микроорганизмы.

Пациентки, инфрицированные U. parvum $(n=90)$ и M. hominis $(n=40)$, были разделены на группы

Таблица 1

Изучение генетической вариабельности генитальных микоплазм

\begin{tabular}{|c|c|c|c|}
\hline & \multicolumn{3}{|c|}{ Микроорганизм } \\
\hline & U. parvum & M. hominis & M. genitalium \\
\hline Размер генома, bp & 751 & 665 & 580 \\
\hline Вариабельный ген & $m b a$ & vaa & $m g 192$ \\
\hline $\begin{array}{l}\text { Праймеры } \\
\text { и их нуклеотидные } \\
\text { последовательности }\end{array}$ & $\begin{array}{c}\text { mba_For } \\
\text { TCTGAGCTATGACATTAGGTGT } \\
\text { mba_Rev } \\
\text { AGTTTCTTTACCTGCTGGTTGT }\end{array}$ & $\begin{array}{c}\text { vaa_For } \\
\text { ACATTATGTGGAATAGCAACTAC } \\
\text { vaa_Rev } \\
\text { AGCTTCTTGAACTCTTGCTCAT }\end{array}$ & $\begin{array}{c}\text { MG192_For } \\
\text { TACCCCAACCAAACCAACTC } \\
\text { MG192_Rev } \\
\text { CTTCGCAATTCATTAGGGGAGACA }\end{array}$ \\
\hline Белок, кодирующий ген & $\begin{array}{c}\text { Мембранный белок MBA (multiple- } \\
\text { banded antigen) }\end{array}$ & $\begin{array}{c}\text { Белок VAA (variable adherence- } \\
\text { associated antigen) }\end{array}$ & Белок P110 \\
\hline Функция белка & Выраженные антигенные свойства & $\begin{array}{c}\text { Участвует в процессах адгезии, } \\
\text { обладает антигенными свойствами }\end{array}$ & $\begin{array}{c}\text { Входит в состав поверхностного } \\
\text { белкового комплекса, участвует } \\
\text { в процессах адгезии }\end{array}$ \\
\hline \multirow[t]{4}{*}{ Генетические варианты } & Серовары & Варианты & Филогенетические группы \\
\hline & Серовар $1(n=21)$ & Вариант I $(n=18)$ & I (2) \\
\hline & Серовар $3(n=35)$ & Вариант II $(n=20)$ & ॥ (2) \\
\hline & Серовар $6(n=32)$ & Вариант III $(n=2)$ & III (4) \\
\hline $\begin{array}{l}\text { Наиболее распространенный } \\
\text { вариант в исследованной } \\
\text { выборке }\end{array}$ & $\begin{array}{c}\text { Cеровар } 3(n=35) \\
38,9 \%\end{array}$ & $\begin{array}{c}\text { Вариант II }(n=20) \\
50,0 \%\end{array}$ & $\begin{array}{l}\text { III (4) } \\
50,0 \%\end{array}$ \\
\hline Вариабельность & Вариабельность 5' конца гена mba & $\begin{array}{c}\text { Специсрический набор генных кассет } \\
\text { гена vaа }\end{array}$ & Последовательность участков гена \\
\hline $\begin{array}{l}\text { Общее количество } \\
\text { исследованных образцов }\end{array}$ & 90 & 40 & 8 \\
\hline Характеристика пациентов & & Женщины в возрасте 20—40 лет & \\
\hline Средний возраст, годы & 23,3 & 24,6 & 25,4 \\
\hline Биологический материал & Соскобы слизистой оболочки урет & ы и цервикального канала, материал отд & ляемого заднего свода влагалища \\
\hline
\end{tabular}


в зависимости от клинических проявлений: пациентки, имевшие клинические и лабораторные признаки воспалительных заболеваний мочеполовой системы: $U$. parvum $(n=45)$, M. hominis $(n=20)$, и пациентки, не имевшие клинических и лабораторных признаков воспалительного процесса мочеполовой системы и обратившиеся для профилактического обследования: U. parvum $(n=45)$, M. hominis $(n=20)$.

Подтверждение наличия воспалительных заболеваний мочеполовой системы основывалось на оценке выраженности лейкоцитарной реакции при микроскопическом исследовании клинического материала. Критериями уретрита и цервицита являлось обнаружение 10 и более полиморфно-ядерных лейкоцитов в поле зрения в отделяемом уретры и цервикального канала соответственно (при просмотре более 5 полей зрения при увеличении светового микроскопа х 1000). Диагноз цервицит устанавливался при наличии лейкоцитоза и слизисто-гнойных выделений из цервикального канала. Диагностическим критерием вагинита являлось изменение соотношения полиморфно-ядерных лейкоцитов к клеткам плоского эпителия более чем 1:1.

Статистическая обработка результатов проводилась с использованием точного критерия Фишера.

\section{Результаты исследования и их обсуждение}

Результаты клинического, лабораторного и молекулярно-генетических исследований приведены в табл. 2-4 и подробно описаны в предыдущих публикациях $[15,16]$.

При обращении жалобы со стороны мочеполовой системы предъявляли 50 (55,6\%) пациенток, инфици-

Таблица 2 Клинические проявления воспалительных заболеваний мочеполовой системы у пациенток, инфицированных генитальными микоплазмами

\begin{tabular}{lccc}
\hline Клинические проявления воспалительных заболеваний & $\begin{array}{c}\text { U. parvum } \\
(\mathrm{n}=90)\end{array}$ & $\begin{array}{c}\text { M. hominis } \\
(\mathrm{n}=40)\end{array}$ & $\begin{array}{c}\text { M. genitalium } \\
(\mathrm{n}=8)\end{array}$ \\
\hline Цервицит & $29(32,2 \%)$ & $20(50,0 \%)$ & $6(75,0 \%)$ \\
\hline Уретрит & $14(15,6 \%)$ & $5(12,5 \%)$ & $4(50,0 \%)$ \\
\hline Вагинит & $12(13,3 \%)$ & $5(12,5 \%)$ & - \\
\hline $\begin{array}{l}\text { Жалобы и лабораторные признаки воспалительных заболеваний } \\
\text { мочеполовой системы отсутствуют }\end{array}$ & $45(50,0 \%)$ & $20(50,0 \%)$ & - \\
\hline Жалобы при обращении со стороны мочеполовой системы & $40(44,4 \%)$ & $19(47,5 \%)$ & $7(87,5 \%)$ \\
\hline
\end{tabular}

\section{Таблица 3 Распределение генетических вариантов генитальных микоплазм у пациенток с различными клини- ческими проявлениями воспалительных заболеваний мочеполовой системы}

\begin{tabular}{|c|c|c|c|c|}
\hline \multirow{2}{*}{ Микроорганизм } & \multirow{2}{*}{ Генетический вариант } & \multicolumn{3}{|c|}{ Клинические проявления } \\
\hline & & цервицит & уретрит & вагинит \\
\hline \multirow{4}{*}{ U. parvum } & Серовар $1(n=21)$ & $8(38,0 \%)$ & $4(19,0 \%)$ & $2(9,5 \%)$ \\
\hline & Серовар $31(n=35)$ & $10(28,5 \%)^{*}$ & $6(17,1 \%)$ & $5(14,3 \%)$ \\
\hline & Серовар $6(n=32)$ & $21(65,6 \%)^{*}$ & $4(12,5 \%)$ & $5(14,6 \%)$ \\
\hline & Серовар 3/Серовар 6 & $p<0,05$ & $p>0,05$ & $p>0,05$ \\
\hline \multirow{4}{*}{ M. hominis } & Вариант I $(n=18)$ & $5(27,8 \%)^{*}$ & $2(11,1 \%)$ & $3(16,7 \%)$ \\
\hline & Вариант II $(n=20)$ & $13(65,0 \%)^{*}$ & $2(10,0 \%)$ & $2(10,0 \%)$ \\
\hline & Вариант III $(n=2)$ & 2 & - & - \\
\hline & Вариант І/Вариант II & $p<0,05$ & $p>0,05$ & $p>0,05$ \\
\hline \multirow{3}{*}{ M. genitalium } & $I(n=2)$ & 2 & 1 & - \\
\hline & $\|(n=2)$ & 2 & 1 & - \\
\hline & III $(n=4)$ & 2 & 2 & - \\
\hline
\end{tabular}

Примечание. * - статистически значимые показатели. 
Таблица 4 Распределение генетических вариантов генитальных микоплазм у пациенток с наличием или отсутствием субъективных признаков воспалительных заболеваний мочеполовой системы

\begin{tabular}{lccc}
\hline Микроорганизм & Генетический вариант & \multicolumn{2}{c}{ Клиническая характеристика } \\
\hline & & $\begin{array}{c}\text { жалобы при обращении со стороны } \\
\text { мочеполовой системы }\end{array}$ & $\begin{array}{c}\text { жалобы и лабораторные признаки воспалительных } \\
\text { заболеваний мочеполовой системы отсутствуют }\end{array}$ \\
\hline \multirow{3}{*}{ U. parvum } & Серовар 1 $(n=21)$ & $9(42,9 \%)$ & $11(52,4 \%)$ \\
\cline { 2 - 4 } & Серовар 3 1(n=35) & $10(28,5 \%)^{*}$ & $24(68,6 \%)$ \\
\hline Серовар 6 $(n=32)$ & $19(59,4 \%)^{*}$ & $10(31,3 \%)$ \\
\hline M. hominis & Вариант I $(n=18)$ & $7(38,9 \%)$ & $11(61,1 \%)$ \\
& Вариант II $(n=20)$ & $10(50,0 \%)$ & $5(10,0 \%)$ \\
\hline
\end{tabular}

Примечание. * — статистически значимые показатели.

рованных U. parvum, 19 (47,5\%) пациенток, инфицированных M. hominis, и 7 (87,5\%) пациенток, инфицированных M. genitalium. Основными субъективными проявлениями воспалительного процесса являлись патологические выделения из половых путей: у 41 (45,6\%) пациентки, инфицированной U. parvum, у 14 (35,0\%) пациенток, инфицированных M. hominis, и 7 (87,5\%) пациенток, инфицированных M. genitalium.

По результатам клинического и лабораторного обследований установлены следующие воспалительные заболевания мочеполовой системы: цервицит у 29 (32,2\%) пациенток, инфицированных U. parvum, у 20 (50,0\%) - инфицированных M. hominis и у $6(75,0 \%)$ - инфрицированных M. genitalium; уретрит - соответственно у 14 (15,6\%), 5 (12,5\%) и 4 (25,0\%); диагноз вагинит установлен у $12(13,3 \%)$ пациенток, инфицированных U. parvum, и у 5 (12,5\%) пациенток, инфицированных M. hominis (см. табл. 2). При этом отмечалась сочетанная локализация воспалительного процесса - клинико-лабораторные признаки цервицита в сочетании с признаками уретрита и/ или вагинита у $8(20,0 \%)$ пациенток, инфицированных M. hominis, и у $5(5,6 \%)$ пациенток, инфицированных U. parvum, а также цервицит в сочетании с уретритом у 3 (37,5\%) пациенток, инфицированных M. genitalium.

Клинические и лабораторные признаки воспаления мочеполовой системы отсутствовали у 45 (50,0\%) пациенток, инфицированных U. parvum, и у 20 (50,0\%) пациенток, инфицированных M. hominis, что определено критериями включения в исследование на этапе формирования групп пациентов для исследования.

В результате проведенного молекулярного типирования U. parvum, M. hominis и M. genitalium были определены три генетических варианта каждого из исследованных микроорганизмов, выделенных из клинического материала пациенток (см. табл. 1). Наиболее распространенный генетический вариант U. parvum у обследованных пациенток серовар 3 - у 38,9\% (35),
M. hominis - вариант II - у 50,0\% (20), M. genitalium фрилогенетическая группа III - у 50,0\% [4].

Для оценки клинической значимости генетических вариантов генитальных микоплазм проведено сравнение частоты идентификации различных генетических вариантов у пациенток с наличием или отсутствием клинических и лабораторных признаков воспалительных заболеваний мочеполовой системы, а также в зависимости от характера воспалительного процесса (см. табл. 3, 4).

Частота идентификации различных генетических вариантов условно-патогенных $U$. parvum и M. hominis у пациенток с наличием или отсутствием признаков воспалительного процесса мочеполовой системы статистически значимо различалась. У пациенток с установленным диагнозом цервицита значимо чаще определяли серовар 6 U. parvum - у 21 (65,6\%) по сравнению с сероваром 3 - у $10(28,5 \%)(p<0,05)$. Также 19 (59,4\%) пациенток, иноицированных сероваром 6 U. parvum, предъявляли жалобы при обращении со стороны мочеполовой системы, в то время как при инфицировании сероваром $3 U$. parvum жалобы при обращении предъявляли лишь 10 (28,5\%) пациенток.

Показано, что инорицирование сероваром 6 U. parvum, который является фрилогенетически наиболее отдаленным от остальных сероваров, чаще, чем инфрицирование фрилогенетически близкими друг к другу сероварами 1 и 3, приводит к развитию воспалительных заболеваний мочеполового тракта, сопровождающихся субъективными проявлениями $(p<0,05)$.

Инфицирование сероваром $3 U$. parvum чаще, чем другими исследованными сероварами, протекает без клинико-лабораторных признаков воспаления мочеполовой системы $(p<0,05)$.

Полученные результаты позволяют предположить, что наличие клинических проявлений воспалительных заболеваний мочеполовой системы у женщин ассоциировано с инфицированием U. parvum серовара 6. 
Значимые различия распределения генетических вариантов M. hominis отмечены у пациенток с установленным диагнозом цервицита. Генетический вариант II M. hominis получен от 13 (65,0\%) пациенток с диагнозом цервицита, в то время как вариант I - только от 5 $(27,8 \%)$ пациенток $(p<0,05)$.

Генетический вариант M. hominis II чаще остальных исследованных вариантов приводит к развитию у женщин воспалительных процессов мочеполовой системы, сопровождающихся клиническими проявлениями. Генетический вариант I M. hominis чаще приводит к бессимптомному инфицированию М. hominis, без клинико-лабораторных признаков воспаления $(p<0,05)$. Полученные данные могут рассматриваться в качестве косвенного подтверждения, что вариабельность поверхностного белка VAA изменяет вирулентность условно-патогенного микроорганизма M. hominis, определяя наличие или отсутствие клинических проявлений воспалительных заболеваний у инфицированных пациенток.

Значимых различий распределения генетических вариантов M. genitalium у обследованных пациенток не установлено.

В ходе исследования выделены образцы M. genitalium, относящиеся к трем различным фрилогенетическим группам по гену $\mathrm{mg} 192$. Полученные данные свидетельствуют о том, что инфицирование M. genitalium, относящимся к любому из идентифицированных филогенетических вариантов, может сопровождаться различными клиническими проявлениями воспалительных заболеваний мочеполовой системы - как уретритом, так и цервицитом.

Вариабельность гена mg192 M. genitalium, возможно, не изменяет или изменяет незначительно свойства поверхностного белка, не снижая или не повышая вирулентность патогенного микроорганизма M. genitalium.

Таким образом, в проведенном исследовании клинические и лабораторные признаки воспалительных заболеваний мочеполовой системы со значимо более высокой частотой определялись у пациенток, инфицированных сероваром $6 U$. parvum или генетическим вариантом II M. hominis.
Полученные данные позволяют предположить, что различный уровень патогенности $U$. parvum и M. hominis может определяться их генетической вариабельностью. В то время как патогенный микроорганизм M. genitalium не проявляет выраженной генетической вариабельности и взаимосвязи генетических вариантов с клиническим течением воспалительных заболеваний мочеполовой системы человека.

\section{Заключение}

В результате проведенного исследования показана генетическая вариабельность образцов U. parvum, M. hominis и M. genitalium, выделенных из клинического материала пациенток (соскоб уретры и цервикального канала). Распределение генетических вариантов U. parvum и M. hominis, полученных от пациенток с различным клиническим течением, позволяет предположить влияние генетической вариабельности на выраженность воспалительного процесса мочеполовой системы и уровень вирулентности микроорганизмов. Генетическая вариабельность инфекционных агентов может играть инициирующую роль в развитии воспалительного процесса мочеполовой системы при взаимодействии с макроорганизмом.

Условия, при которых условно-патогенный микроорганизм проявляет свои патогенные свойства, могут определяться не только окружающей средой, но и генетическими особенностями микроорганизма. Возможно, факторы, определяющие вирулентность условно-патогенных генитальных микоплазм (U. parvum, M. hominis), обладают более выраженной вариабельностью, чем патогенного M. genitalium.

Определение генетических особенностей отдельных штаммов и типов должно позволить персонализировать тактику ведения пациентов. Выявление наиболее вирулентного генетического варианта микроорганизма в клиническом материале открывает возможность подбирать адекватную, индивидуальную терапию в каждом случае или устанавливать необходимость проведения терапии при инфицировании условно-патогенными микроорганизмами. [ 


\section{Литература}

1. Pereyre S., Sirand-Pugnet P., Beven L. et al. Life on Arginine for Mycoplasma hominis: clues from its minimal genome and comparison with other human urogenital Mycoplasmas. PLOS Genet 5. 10. 2010.

2. Waites K, Talkington D (2005) New developments in human diseases due to mycoplasmas. In: Blanchard A, Browning GF, eds. Mycoplasmas molecular biology pathogenicity and strategies for control. Norfolk: Horizon bioscience. P. 289-354.

3. Robertson J.A., Stemke G.W., Davis J.W., Jr., Harasawa R., Thirkell D. et al. (2002) Proposal of Ureaplasma parvum sp. nov. and emended description of Ureaplasma urealyticum (Shepard et al. 1974) Robertson et al. 2001. Int J Syst Evol Microbiol 52: 587-597.

4. Glass J.I., Lefkowitz E.J., Glass J.S., Heiner C.R., Chen E.Y., Cassell G.H.: The complete sequence of the mucosal pathogen Ureaplasma urealyticum. Nature 2000, 407: 757-762.

5. Peterson S.N., Fraser C. M.The complexity of simplicity. Genome Biology. USA 2001, 2.

6. Woese C.R., Maniloff J., Zablen L.B.: Phylogenetic analysis of the mycoplasmas. ProcNatIAcadSci USA 1980, 77: 494—498.

7. Glass J.I., Lefkowitz E.J., Glass J.S., Heiner C.R., Chen E.Y. et al. (2000) The complete sequence of the mucosal pathogen Ureaplasma urealyticum. Nature 407: 757-762.
8. Borhsenius S.N., Chernova O.A., Chernov V.M., Vonskij M.S. Mikoplazmy. Mikoplazmy: Molekuljarnaja i kletochnaja biologija, vzaimodejstvie s immunnoj sistemoj mlekopitajushhih, patogennost', diagnostika-SPb: Nauka. 2002 - 319. [Борхсениус С.Н., Чернова О.А., Чернов В.М., Вонский М.С. Микоплазмы. Микоплазмы: Молекулярная и клеточная биология, взаимодействие с иммунной системой млекопитающих, патогенность, диагностикаСПб: Наука. 2002 - 319.]

9. Kong F., Ma Z., James G., Gordon S., Gilbert G.L. Molecular genotyping of human Ureaplasma species based on multiple-banded antigen (MBA) gene sequences.Int J SystEvolMicrobiol 2000; 50 Pt 5: 1921—1929.

10. Dando S.J., Nitsos I., Kallapur S.G., Newnham J.P., Polglase G.R., Pillow J.J., Jobe A.H., Timms P., Knox C.L. The role of the multiple banded antigen of Ureaplasma parvum in intraamniotic infection: major virulence factor or decoy? PLoS One 2012; 7 (1): 29856.

11. Boesen.T., Emmersen J. et al. The Mycoplasma hominis vaa gene displays a mosaic gene structure. Molecular Microbiology 1998; 29 : 97-110.

12. Boesen.T., Fedosova N., Kjeldgaard M. et al. Molecular design of Mycoplasma hominis Vaa adhesin. Protein Science/ 2001, 10: $2577-2586$.
13. Gorshkov 0.V., Chernov V.V. et al. Genetic polymorphism of Mycoplasma variability of cytoadhesin genes in clinical isolates of Mycoplasma hominis. Biochemistry and biophysics. 2005;404: 328-331.

14. Liang Ma, Jørgen S. Jensen, Miriam Mancuso, Ryoichi Hamasuna, Qiuyao Jia, Chris L. McGowin, David H. Martin.Genetic Variation in the Complete MgPa Operon and Its Repetitive Chromosomal Elements in Clinical Strains of Mycoplasma genitalium. PLoS One. 2010; 5 (12).

15. Rahmatulina M.R. Geneticheskie varianty U. parvum i in rol' v razvitii vospalitel'nyh zabolevanij mochepolovoj sistemy. /Rahmatulina M.R., Plahova K.I., Igonina 0.N. Vestnik dermatologii i venerologii. 2014; 3. S. 79—84. [Рахматулина М.P. Генетические варианты U. parvuт и их роль в развитии воспалительных заболеваний мочеполовой системы. /Рахматулина М.Р., Плахова К.И., Игонина О.Н. Вестник дерматологии и венерологии. 2014; (3). С. 79—84.]

16. Rahmatulina M.R. Geneticheskie varianty genital'nyh mikoplazm i ih vzaimosvjaz' s klinicheskim techeniem vospalitel'nyh zabolevanij mochepolovoj sistemy u zhenshhin. / Rahmatulina M.R., Plahova K.I., Kubanov A.A. Vestnik dermatologii i venerologii. 2014; 6. S. 107-114. [Рахматулина М.Р. Генетические варианты генитальных микоплазм и их взаимосвязь с клиническим течением воспалительных заболеваний мочеполовой системы у женщин. / Рахматулина М.Р., Плахова К.И., Кубанов А.А. Вестник дерматологии и венерологии. 2014; (6). С. 107-114.]

об авторе:

К.И. Плахова - Д.М.н., старший научный сотрудник отдела ИППП ФГБУ «ГНЦДК» Минздрава России, Москва

Консликт интересов

Автор заявляет об отсутствии потенциального конфрликта интересов, требующего раскрытия в данной статье 